\title{
Systematic review of international clinical guidelines for the promotion of physical activity for the primary prevention of cardiovascular diseases
}

\author{
N. Aerts ${ }^{1 *}$, D. Le Goff², M. Odorico ${ }^{2}$, J. Y. Le Reste², P.Van Bogaert ${ }^{3}$, L. Peremans ${ }^{1,3}$, G. Musinguzi ${ }^{1,4}$, \\ P. Van Royen ${ }^{1}$ and $\mathrm{H}$. Bastiaens ${ }^{1}$
}

\begin{abstract}
Background: Cardiovascular diseases are the world's leading cause of morbidity and mortality. An active lifestyle is one of the cornerstones in the primary prevention of cardiovascular disease. An initial step in guiding primary prevention programs is to refer to clinical guidelines. We aimed to systematically review clinical practice guidelines on primary prevention of cardiovascular disease and their recommendations regarding physical activity.

Methods: We systematically searched Trip Medical Database, PubMed and Guidelines International Network from January 2012 up to December 2020 using the following search strings: 'cardiovascular disease,',prevention', combined with specific cardiovascular disease risk factors. The identified records were screened for relevance and content. We methodologically assessed the selected guidelines using the AGREE II tool. Recommendations were summarized using a consensus-developed extraction form.

Results: After screening, 27 clinical practice guidelines were included, all of which were developed in Western countries and showed consistent rigor of development. Guidelines were consistent about the benefit of regular, moderateintensity, aerobic physical activity. However, recommendations on strategies to achieve and sustain behavior change varied. Multicomponent interventions, comprising education, counseling and self-management support, are recommended to be delivered by various providers in primary health care or community settings. Guidelines advise to embed patient-centered care and behavioral change techniques in prevention programs.

Conclusions: Current clinical practice guidelines recommend similar PA lifestyle advice and propose various delivery models to be considered in the design of such interventions. Guidelines identify a gap in evidence on the implementation of these recommendations into practice.
\end{abstract}

Keywords: Systematic review, Clinical practice guidelines, Cardiovascular disease, Primary prevention, Behavior change, Lifestyle advice, Cardiovascular risk reduction

\footnotetext{
*Correspondence: naomi.aerts@uantwerpen.be

${ }^{1}$ Department of Primary and Interdisciplinary Care, Faculty of Medicine

and Health Sciences, University of Antwerp, Antwerp, Belgium

Full list of author information is available at the end of the article
}

(C) The Author(s) 2021. Open Access This article is licensed under a Creative Commons Attribution 4.0 International License, which permits use, sharing, adaptation, distribution and reproduction in any medium or format, as long as you give appropriate credit to the original author(s) and the source, provide a link to the Creative Commons licence, and indicate if changes were made. The images or other third party material in this article are included in the article's Creative Commons licence, unless indicated otherwise in a credit line to the material. If material is not included in the article's Creative Commons licence and your intended use is not permitted by statutory regulation or exceeds the permitted use, you will need to obtain permission directly from the copyright holder. To view a copy of this licence, visit http://creativecommons.org/licenses/by/4.0/. The Creative Commons Public Domain Dedication waiver (http://creativeco mmons.org/publicdomain/zero/1.0/) applies to the data made available in this article, unless otherwise stated in a credit line to the data. 


\section{Background}

Cardiovascular diseases (CVDs) are the number one cause of death worldwide; more people die annually from CVDs than from any other cause. In 2016 alone, an estimated 17.9 million people died from CVDs, accounting for $31 \%$ of global mortality. According to estimates of the World Health Organization, nearly $75 \%$ of vascular events may be prevented when a combination of costeffective population-wide and individual interventions are implemented appropriately [1]. Addressing modifiable CVD risk factors can prevent disability and death, and improve quality of life. The most important behavioral risk factors of heart disease and stroke are physical inactivity, unhealthy diet, tobacco use and harmful use of alcohol [2,3].

Current literature demonstrates numerous methods to reduce CVD risk profile with strong consensus regarding lifestyle behavior. Primary prevention is an important priority for all developers of health policy [4]. Physical activity (PA) is one of the main targeted areas in CVD primary prevention, nested within a broader lifestyle approach and besides medical treatment [5]. Although countries are facing an overall pandemic of physical inactivity similar to that of smoking, the response to the public health challenge of inactivity has not been as strong as needed [6]. Worldwide, one in four adults and three in four adolescents currently do not meet the global recommendations for PA set by the World Health Organization. In some countries, levels of attainment of PA guidelines can be as low as $30 \%$ and inactivity accounts for $1-3 \%$ of national health care costs [7]. Evidence shows that adults stand to gain substantial longevity benefits by becoming more physically active, irrespective of established CVD risk factors. Increasing and maintaining PA levels to meet the minimum public health recommendations can prevent nearly one in two deaths associated with physical inactivity [8].

Despite high evidence on the importance of lifestyle behavior change interventions, implementation in practice remains limited [9]. Horizon 2020 project SPICES ${ }^{1}$ aims to implement a program, containing PA behavior interventions, for the primary prevention of CVD in primary health care and community settings in various high (Belgium, France, United Kingdom), middle (South Africa) and low (Uganda) income contexts. As improving the efficiency of disseminating the evidence-based practices to practitioners is often seen as a solution for bridging the science-to-practice gap [10], a first step for

\footnotetext{
${ }^{1}$ Scaling-up Packages of Interventions for Cardiovascular disease prevention in selected sites in Europe and Sub-Saharan Africa: An implementation research - European Commission.
}

us was to explore the guidelines in order to inform the SPICES program, before evaluating further implementation thereof. Clinical practice guidelines (CPGs) organize and provide the best available evidence to support clinical decision making [11]. Systematically reviewing existing CPGs is an approach that has been used before, however, to our knowledge, no recent study exists that systematically reviewed international CPGs with a focus on PA in the primary prevention of CVD. Our aim is to review guidelines in order to identify best practice recommendations in terms of the design and implementation of interventions, e.g. setting; intervention deliverers; intervention content, for the implementation and evaluation in the Horizon 2020 project SPICES sites.

This systematic review aims to answer the following research question: What recommendations are made in CPGs to guide the design and the implementation of PA interventions in primary health care and at community level, for the primary prevention of CVD?

\section{Methods}

We applied standard systematic review methodology as outlined by the Cochrane Collaboration [12] and we used the PRISMA ${ }^{2}$ checklist [13] (Additional file 1) for selfevaluation of the overall standards and quality requirements for reporting a systematic literature review. All authors contributed to the development of the research protocol prior to the study.

Between September 2017 and January 2018, NA, PVR and HB carried out a systematic search on Trip Medical Database and International Guidelines Library of the Guidelines International Network (G-I-N) to reach a broad scope of CPGs. An additional systematic search was subsequently carried out on G-I-N and PubMed in December 2020, with the aim of updating the results of this review with the most recently published guidelines. Suitable search strategies were developed for each database, using multiple combinations of free text, $\mathrm{MeSH}$ terms, word variants, Boolean operators and truncation for: 'cardiovascular disease,' 'prevention', 'risk', 'lifestyle', 'physical activity'. Publication type was restricted to 'guidelines', the status was specified to be published or under review and language was restricted to English, Dutch and French.

All records were submitted to a selection procedure on relevance and content, by means of pre-defined in- and exclusion criteria. Publication types other than CPGs and those published before January 2012 were excluded from this review. In case of different versions of the same CPG, we included the most recent one. Titles and abstracts

\footnotetext{
${ }^{2}$ Preferred Reporting Items for Systematic Reviews and Meta-Analyses.
} 
were independently screened by NA, DLG and MO. Records were excluded if both reviewers agreed they were not eligible; discrepancies between reviewers were resolved by discussion until consensus (NA, DLG, MO, JYLR, HB).

CPGs were included if the recommendations described PA interventions for primary prevention of CVD, in comparison to other (lifestyle) intervention or no intervention, targeting the general, adult population. Guidelines needed to report on at least one relevant patient outcome measure commonly used for CVD risk assessment, such as CVD mortality and morbidity, or modifiable risk factors in relation to the primary prevention of CVD (e.g. overweight and obesity, hyperlipidemia, hypertension, lifestyle behavior, dysglycemia). Interventions had to be implemented in primary health care or community settings.

CPGs were excluded if they focused exclusively on CVD risk assessment, pharmacological interventions or lifestyle interventions other than exercise (diet, smoking, alcohol), or if they were explicitly targeting children, adolescents or a geriatric population. Guidelines addressing secondary prevention of CVD, specific conditions related to CVD (e.g. familial hypercholesterolemia, chronic kidney disease, type I diabetes mellitus) and the management of CVD risk factors beyond primary prevention, were excluded from this review as well.

At least two researchers (NA, MO, DLG, JYLR, PVR, PVB, HB) independently performed a quality appraisal of full text records with the $\mathrm{AGREE}^{3}$ II instrument. The tool comprises 23 items, organized into six domains: scope and purpose, stakeholder involvement, rigor of development, clarity of presentation, applicability and editorial independence [14]. The reviewers' overall assessment (scores from 0 to 7 , with a consensus-based cut off at a minimum score of $5 / 7$ for inclusion) in combination with a positive advice on use of the guideline ('yes' for inclusion), determined the in- or exclusion of each CPG. Records with scores below 5 or around cutoff (one score 4 and one score 5), were excluded. Discrepant scores (more than 1-point difference and one score above 4) and reviewers' recommendations regarding use of the guideline were discussed until we reached a consensual decision by pooling the data.

In order to ensure accuracy of data extraction for this literature review, an author-team consensus-based data extraction form was determined, comprising of three phases. NA extracted the data, regularly conferring with the senior research team (PVR, LP, PVB, GM, HB).

\footnotetext{
${ }^{3}$ Appraisal of Guidelines for Research and Evaluation.
}

Firstly, we listed all included CPGs and extracted publication year (or year of latest update), country, developing organization, language and title. Secondly, we made an inventory of all PA recommendations, stand alone or as a component of a broader lifestyle recommendation, in order to get an overview of the relevant content of each included CPG with regards to our research questions. If reported, the following characteristics were extracted from each recommendation and its scientific underpinning: strength of recommendation and level of evidence, intervention description and outcomes, implementation strategies, evidence gaps.

Thirdly, two core recommendation matrices (Additional files 2 and 3, to read together with Supplementary material 4 - Grading) were produced: with a listing of relevant recommendations for each CPG; entailing detailed information on clinical relevance and level of evidence grades, primary study intervention characteristics and reported outcomes. Taking into consideration cross-guideline recurrence, results were summarized in Tables 2 and 3 .

\section{Results}

Our systematic searches retrieved a total of 826 records. After rejection of 757 records based on title and 6 duplicates, 63 CPGs were eligible for full text screening. Finally, 47 CPGs could be withheld, 20 of which did not meet the minimum quality appraisal criteria according to AGREE II. A summary of the full search and review process is presented in a PRISMA flow chart [13] in Fig. 1.

Table 1 summarizes the basic characteristics of the 27 included CPGs, all of which were developed in Western countries. CPGs were categorized according to their main focus. Seven were dedicated entirely to the global prevention of CVD and a further three to lifestyle behavior (LSt), whereas the other CPGs addressed prevention at the level of specific CVD risk factors: seven records on weight management (OW), four on blood lipids (LCh), three on blood pressure control (BP) and three on blood glucose (DM). All included CPGs met the pre-defined minimum quality according to AGREE II criteria. The domain scores showed some variability. Lowest scores were obtained in domain 5 'applicability' (mean 58\% [range 25-78\%]), highest scores were reached in domain 4 'clarity of development' (median 79\% [range 56-94\%]). (Additional file5 - AGREE Scores).

The information from the guidelines could be divided into two major categories, including content of PA recommendations and delivery of PA interventions. Table 2 contains all recommendations related to the content of PA interventions; Table 3 contains all recommendations involving the delivery of PA interventions. 


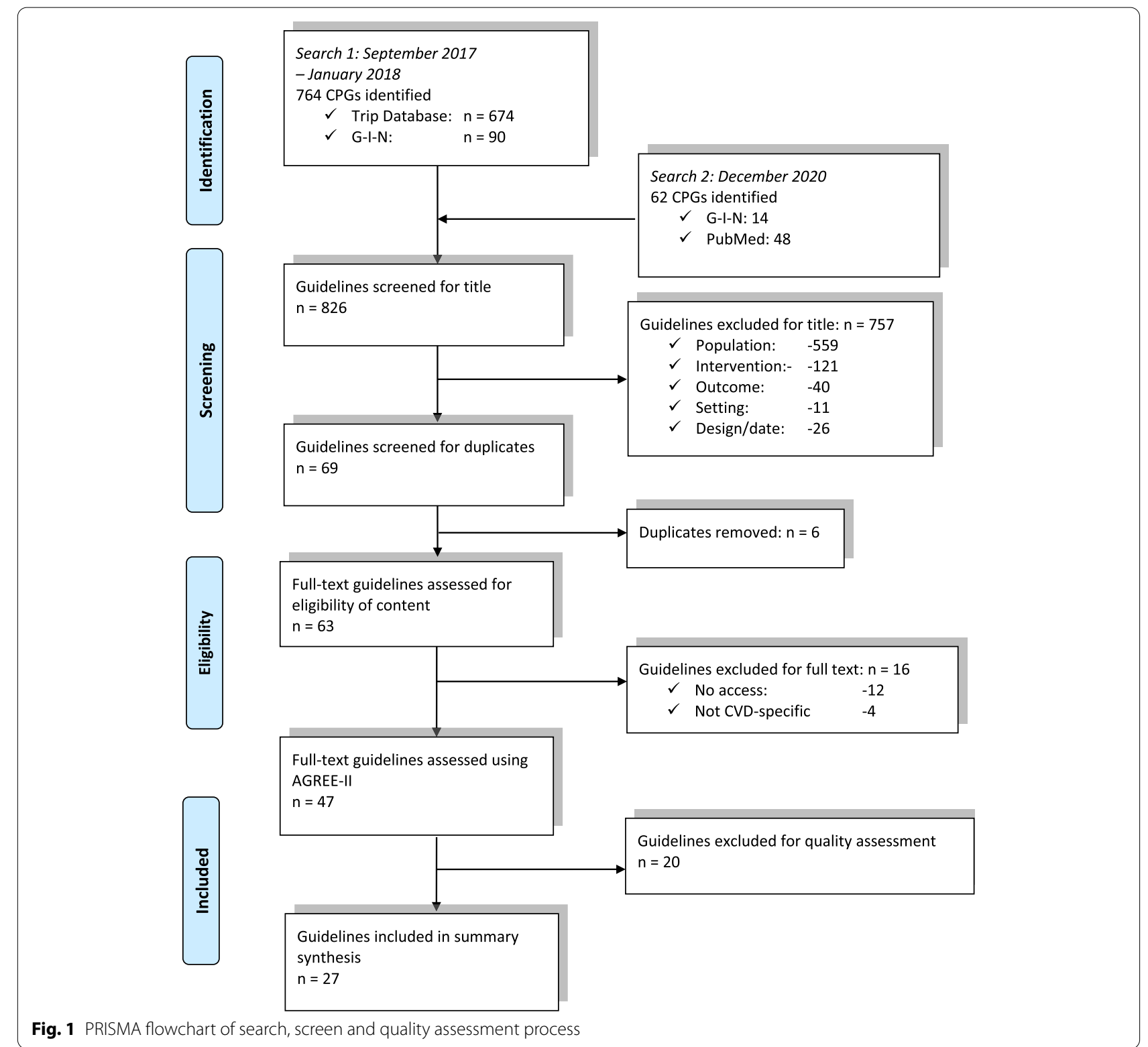

In the included guidelines, PA for the primary prevention of CVD was described by four dimensions: intensity, duration, frequency and type of the recommended PA activity. All CPGs advised interventions to involve moderate to vigorous PA intensity and a duration of PA sessions of at least 150 min weekly for moderate, or at least 75 min weekly for vigorous intensity PA. Four CPGs reported that several shorter PA sessions were as effective as one session of 30 min daily as they provided a similar total energy expenditure [17, 18, 21, 28]. The CPGs stated that PA should be conducted on a regular basis, meaning on at least five days of the week, preferably each day of the week $[16,20]$. Aerobic PA was reported to be the fundamental type of PA for the primary prevention of CVD in eight of the included guidelines [17, 18, 23, 27, 28, 32, 35, 36], which should entail occupational, leisure time, exercise and/or active living activities. Two guidelines recommended interventions with a combination of both aerobic and resistance training for the prevention of diabetes and its CVD complications [17, 41]. Three other guidelines advised on including resistance training or muscle strengthening exercises for the primary prevention of CVD, such as carrying heavy load, heavy gardening, weight training, push-ups or sit-ups on at least two days a week [18, 19, 32], whereas three other CPGs merely stated that there 


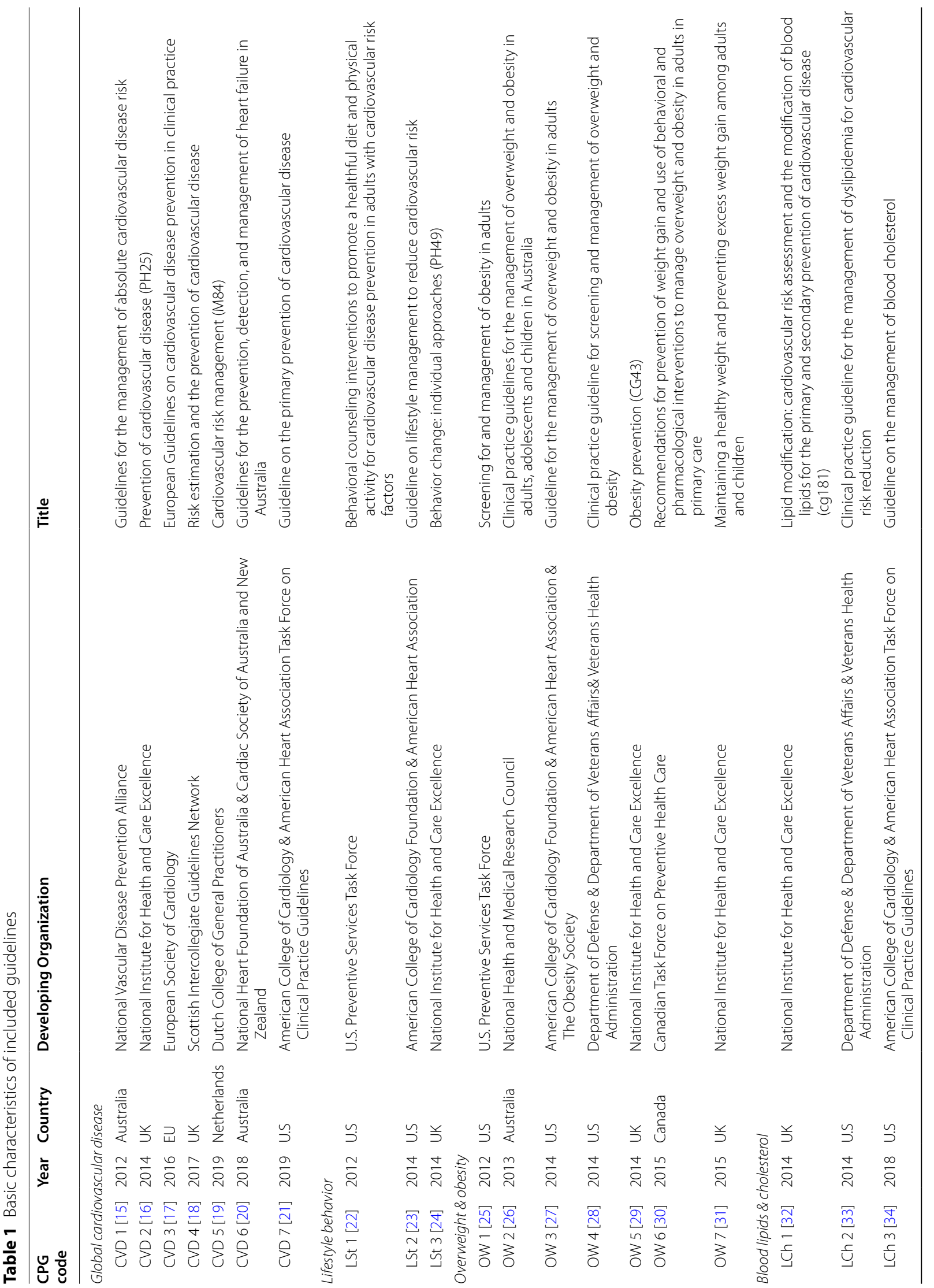




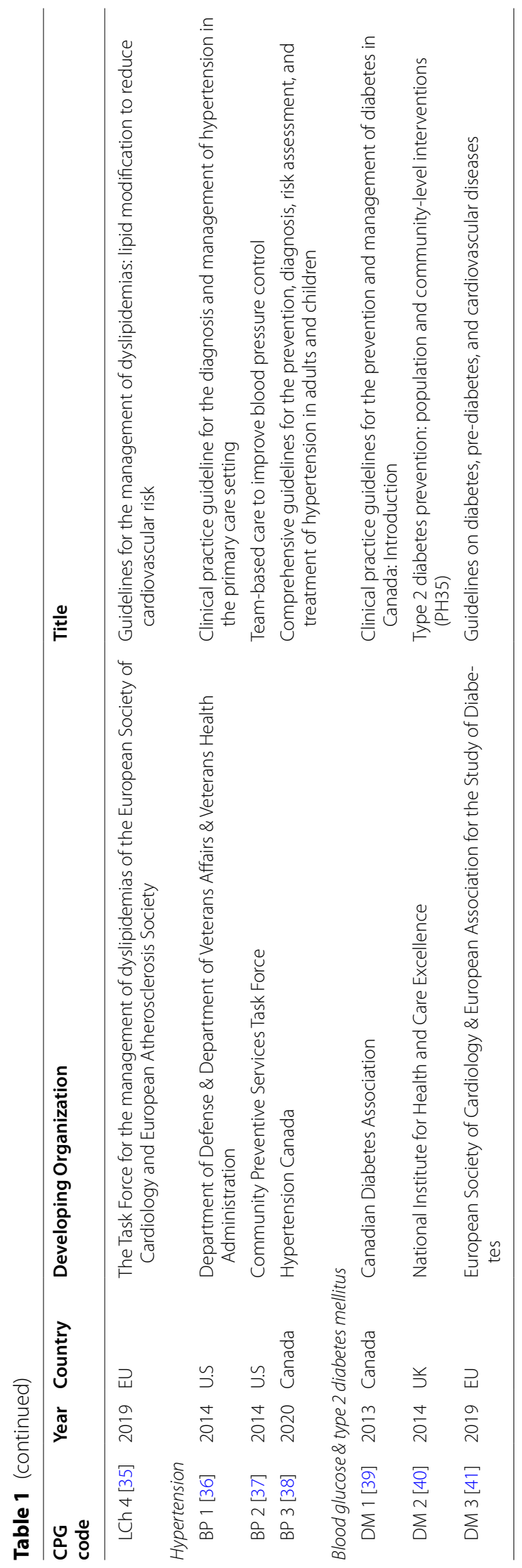




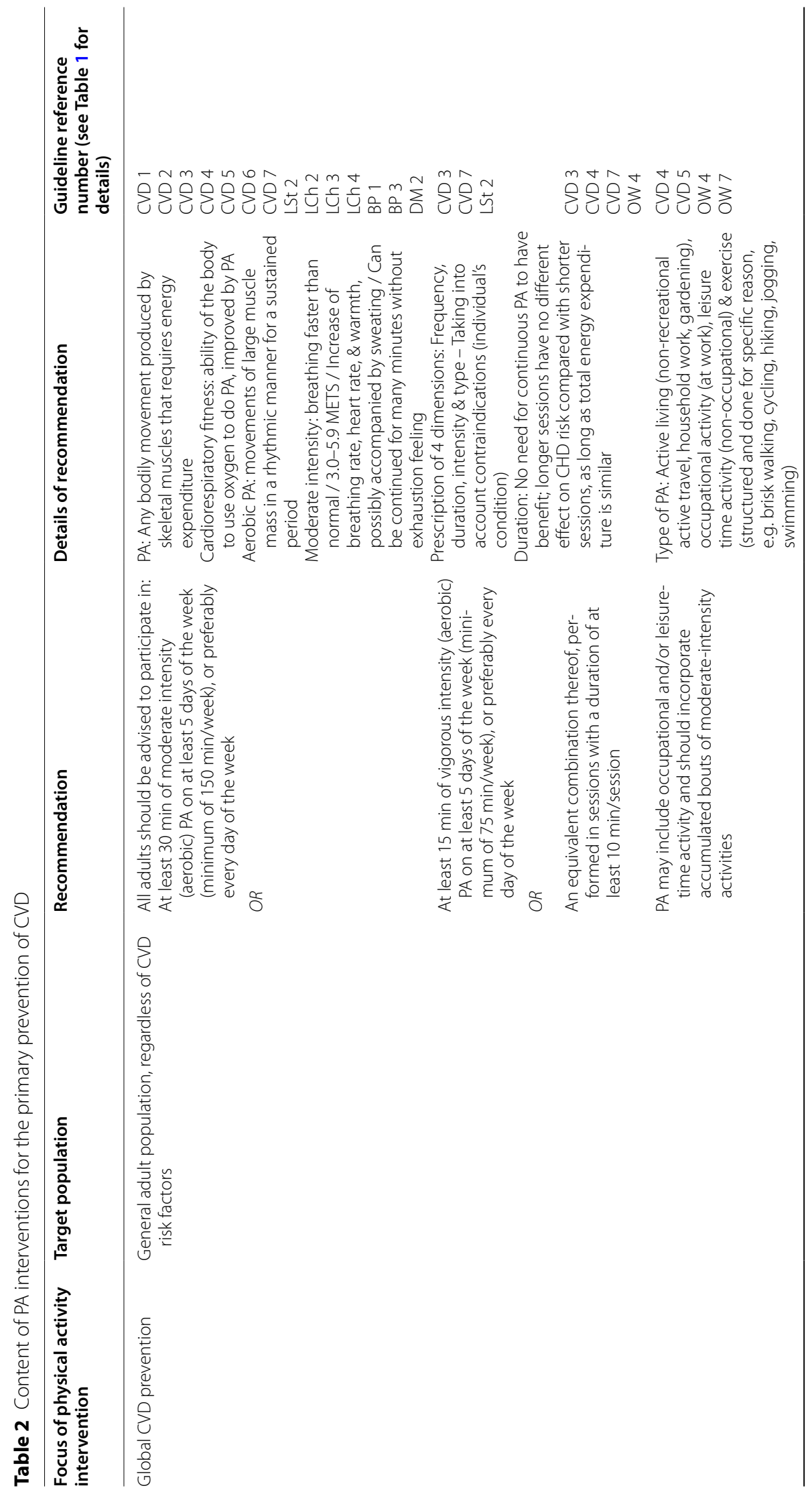




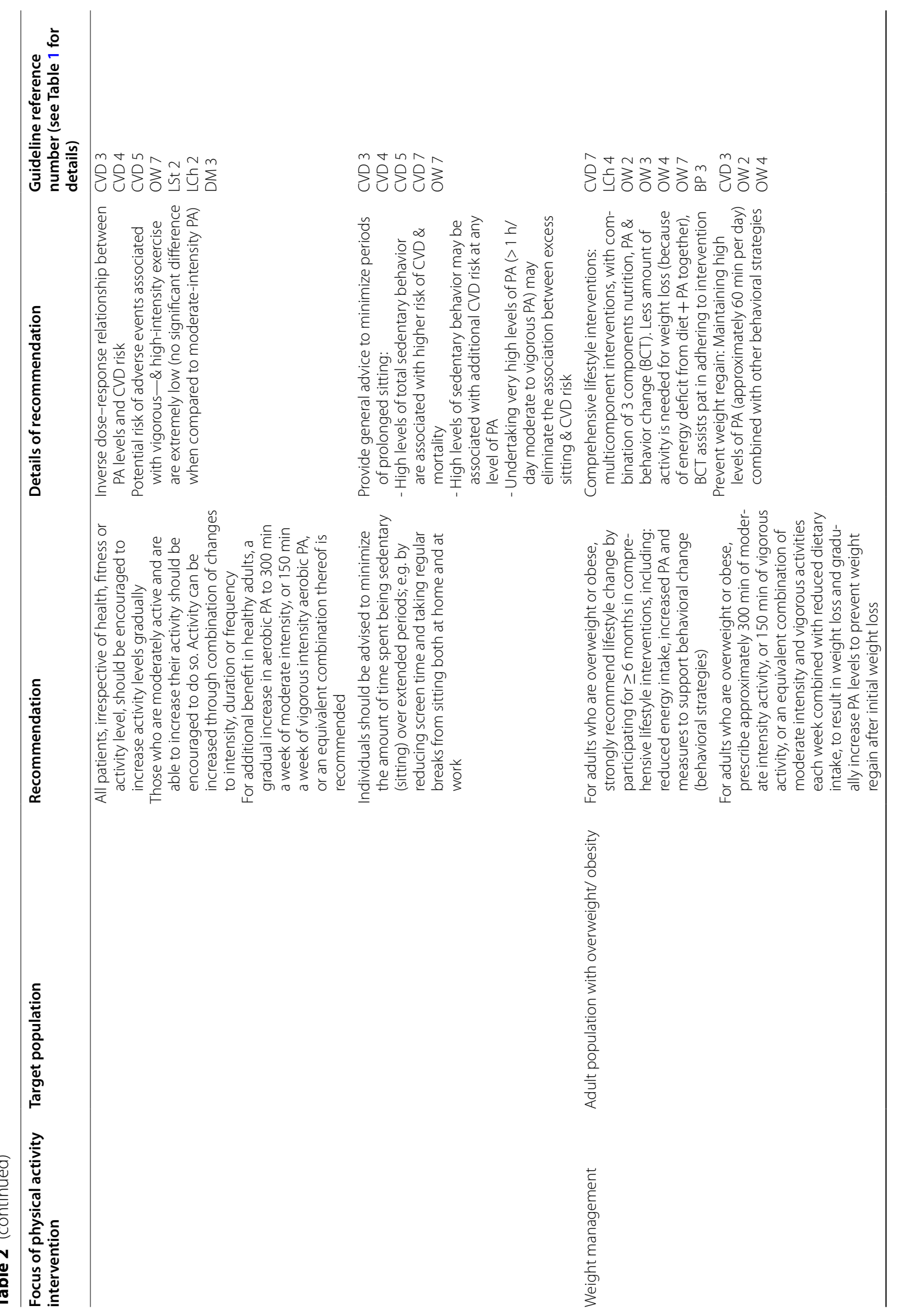




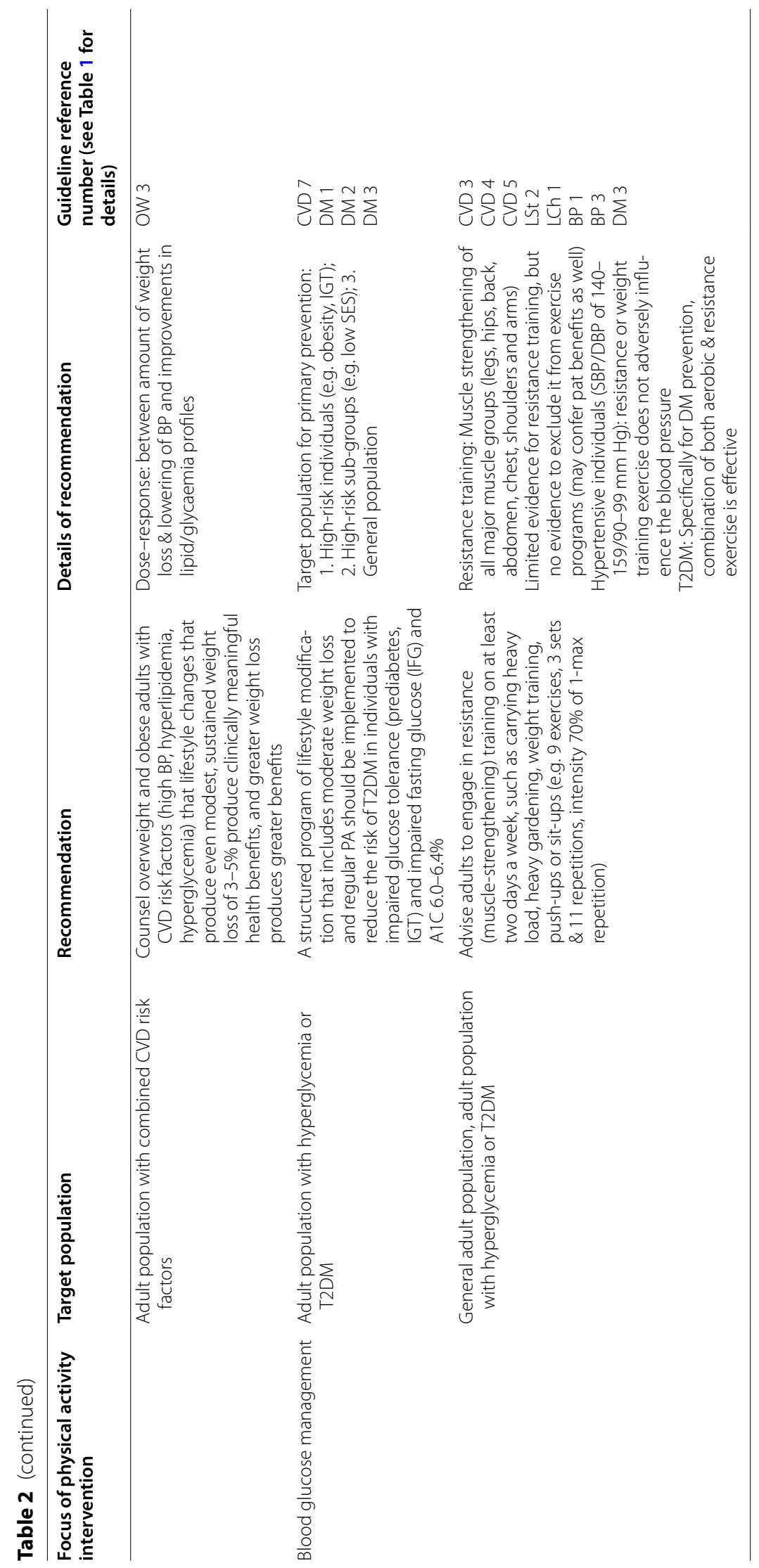




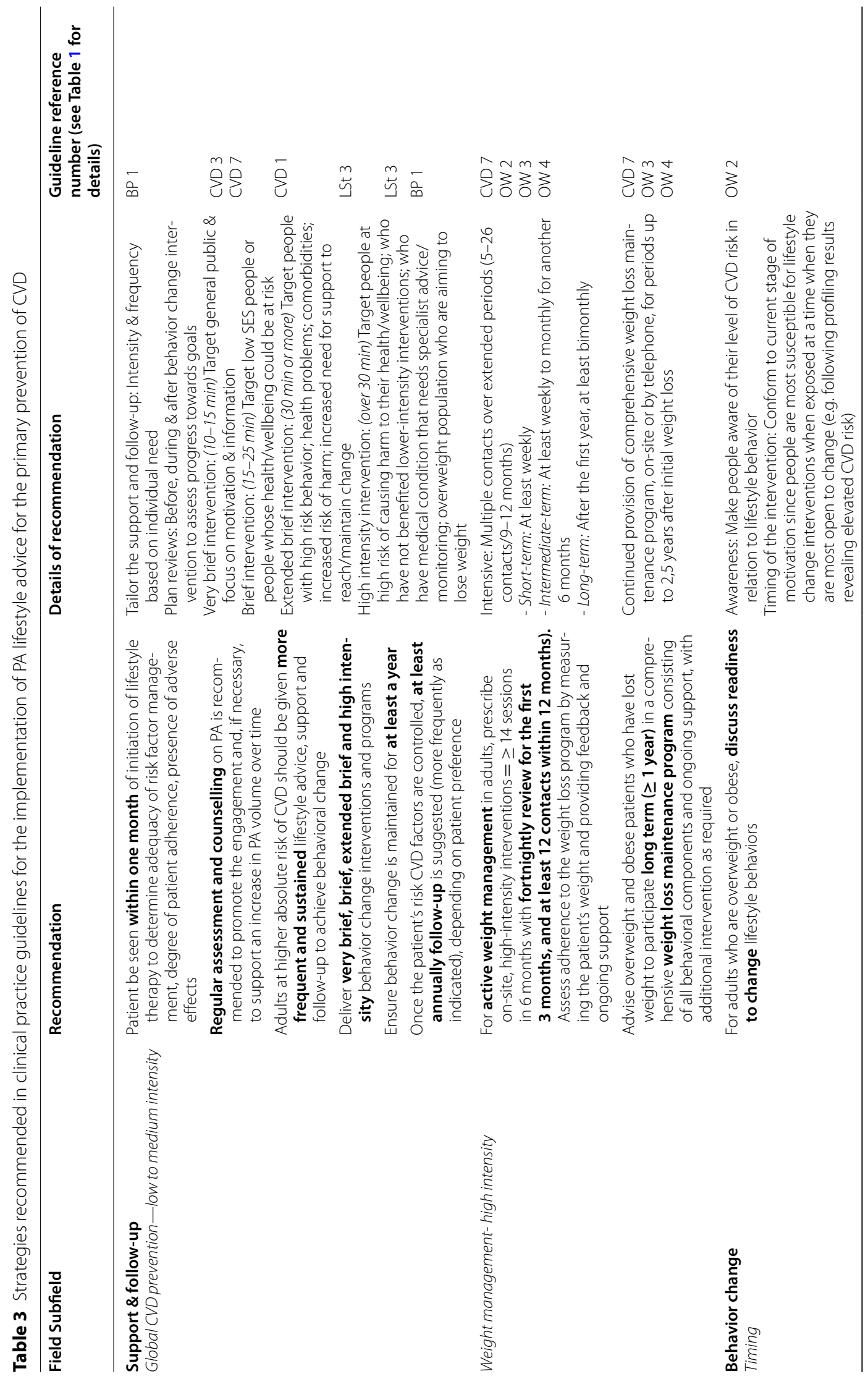




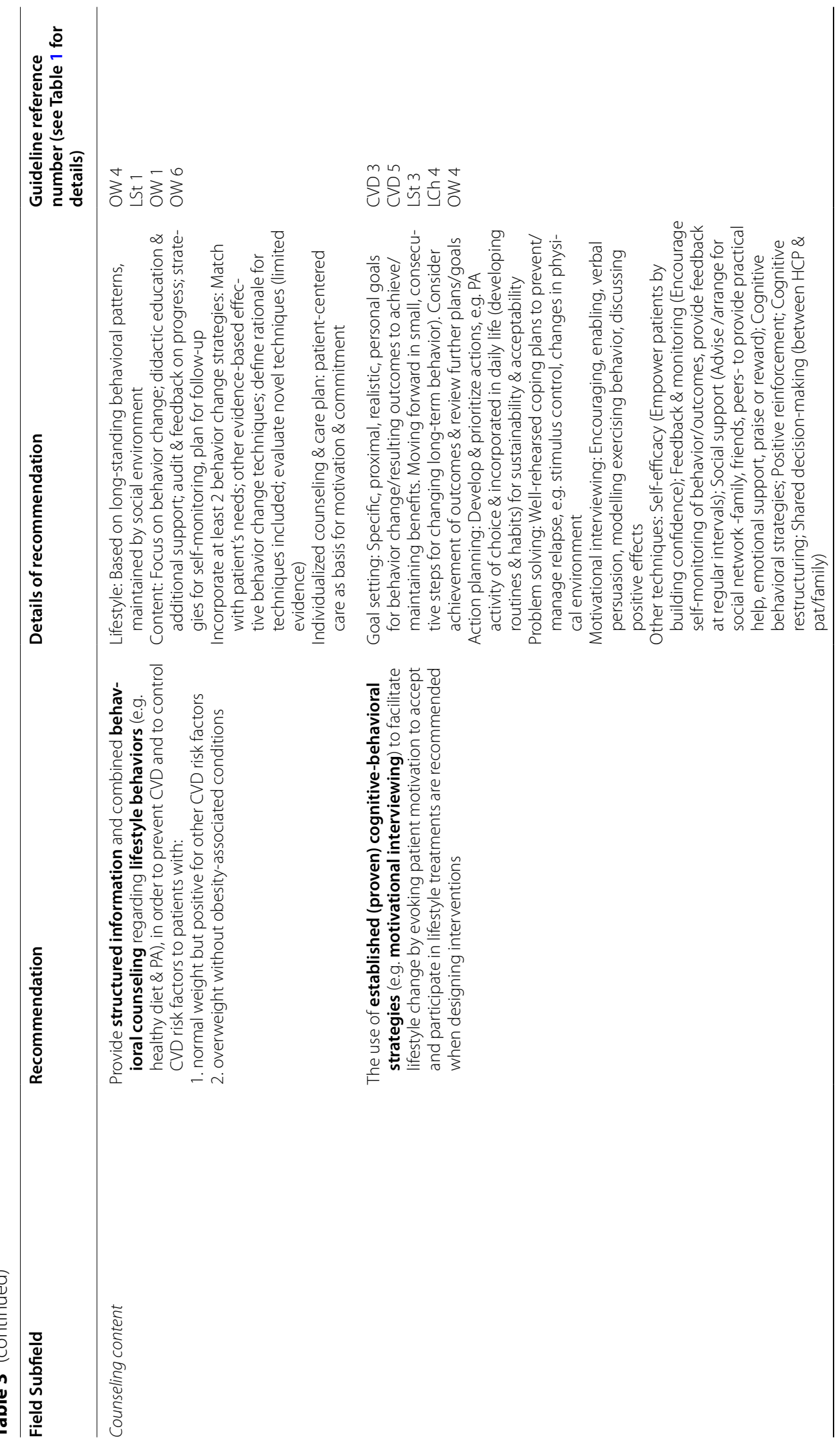




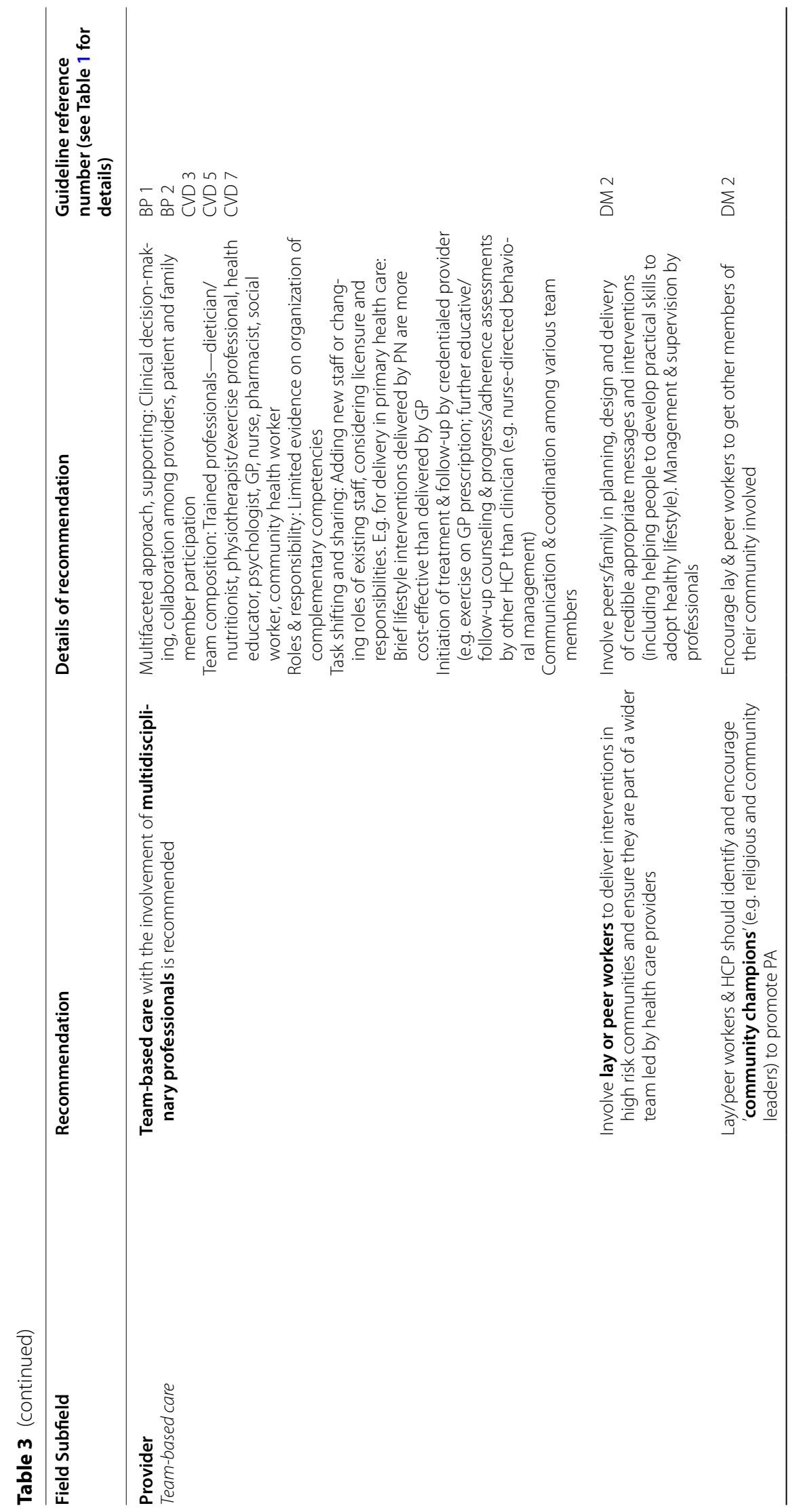




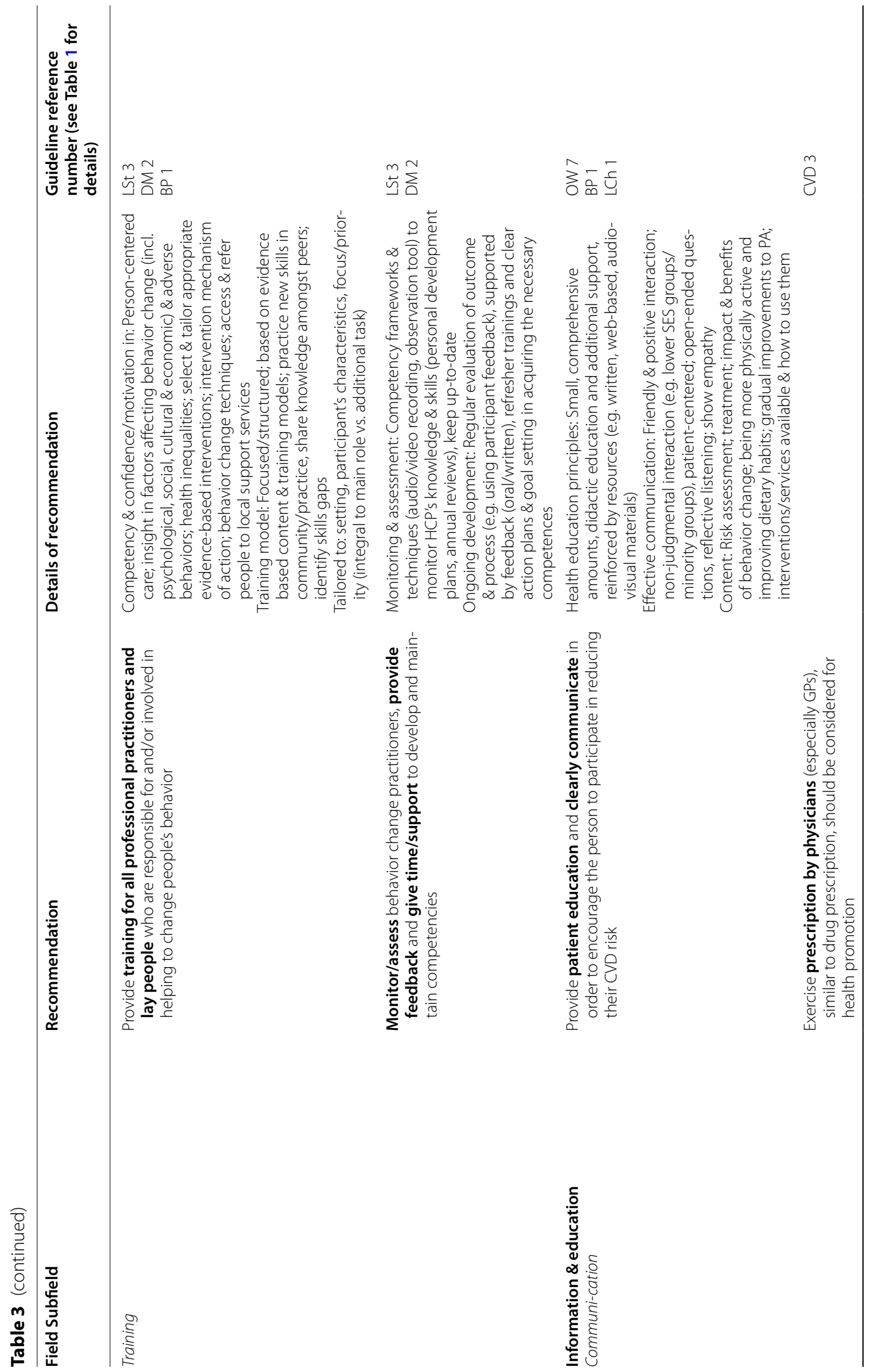




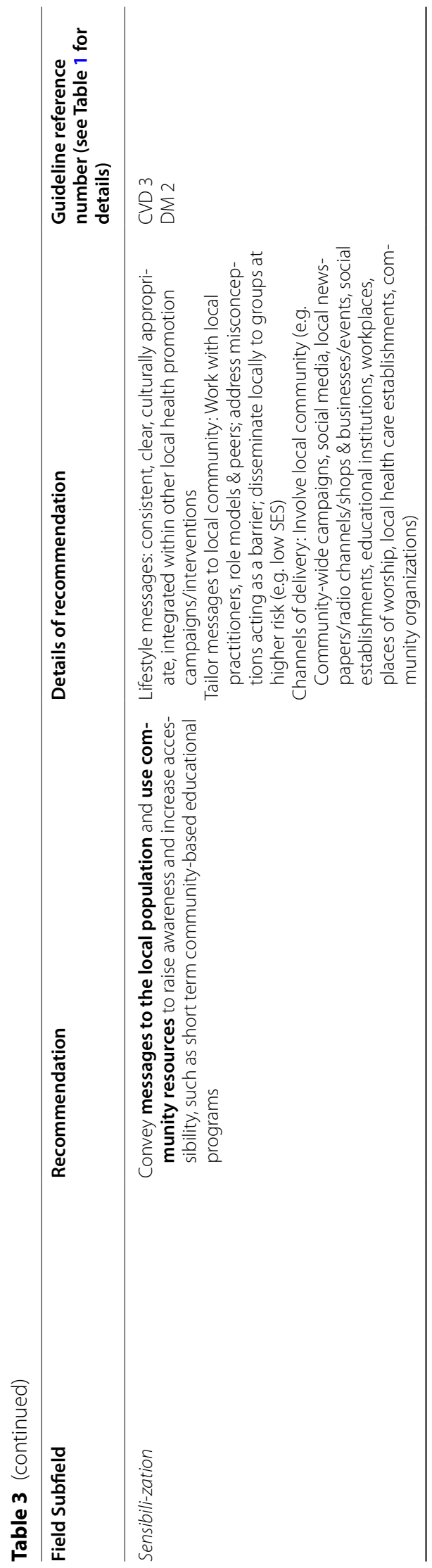




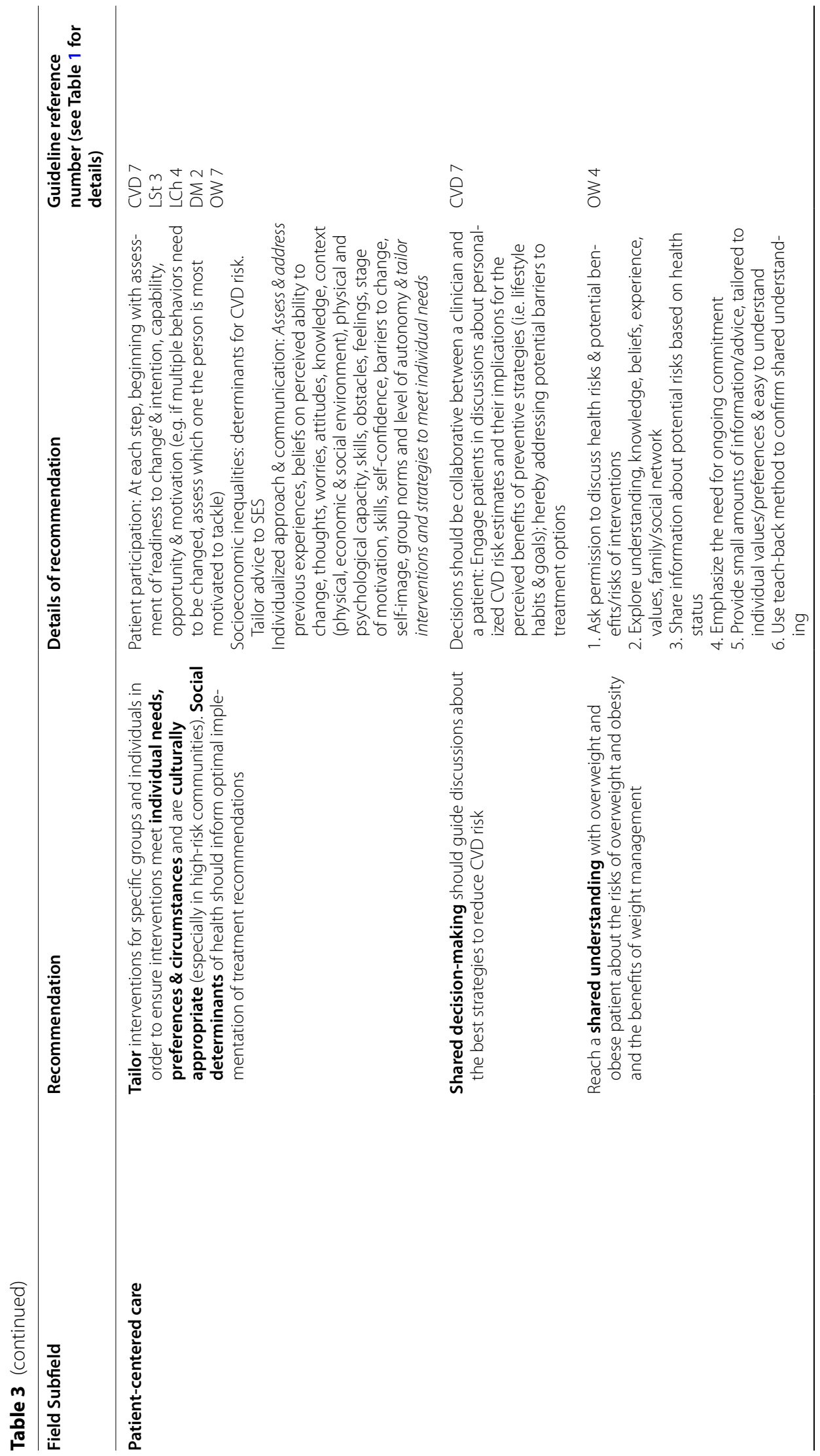




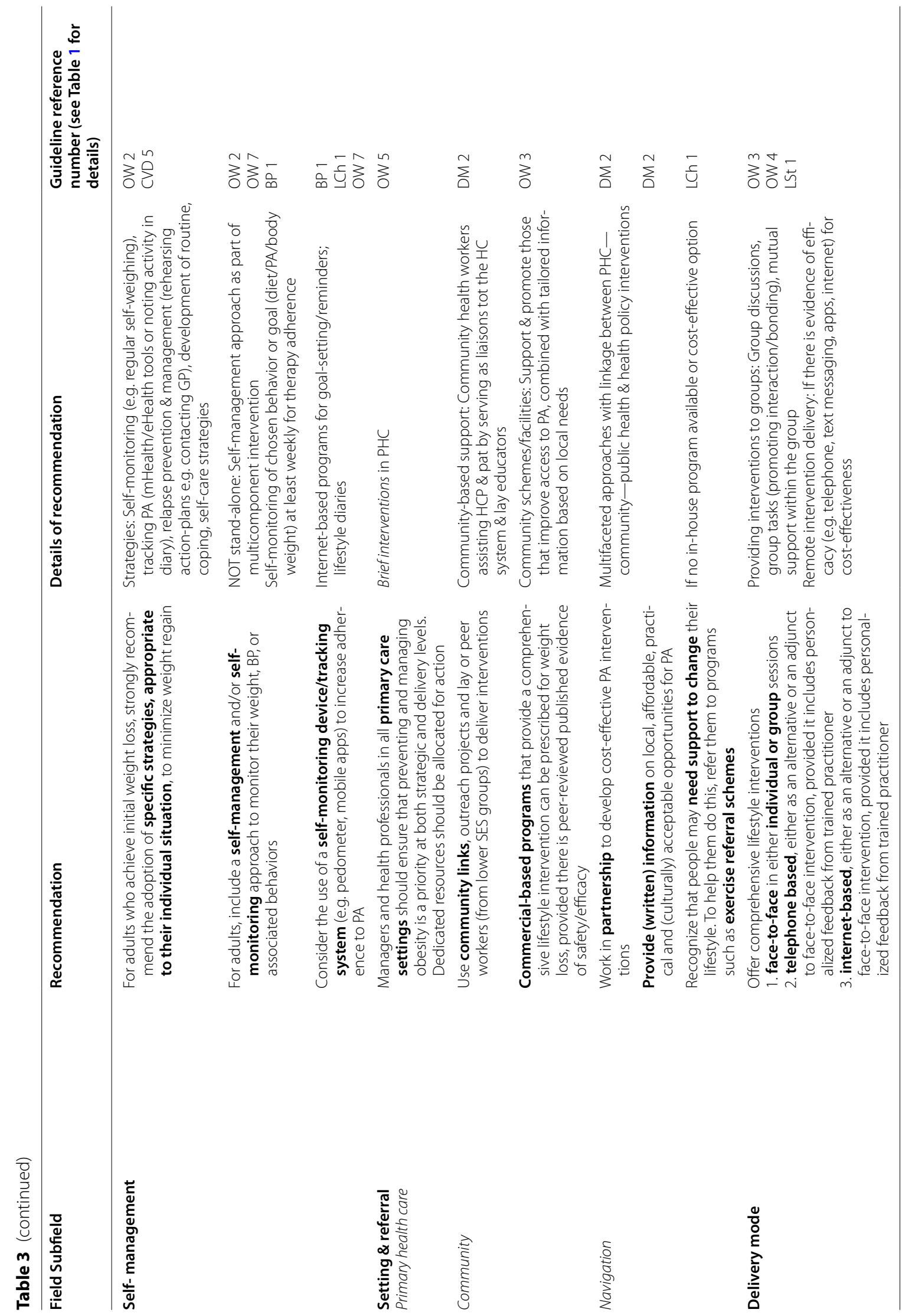


is no evidence for excluding it from interventions [23, 36, 38].

Due to the inverse dose-response relationship between higher levels of PA and lower risk of CVD events as reported in the CPGs [18, 23, 33], a gradual increase of PA levels through a combination of changes to intensity, duration and/or frequency [17-19, 31, 41] should be encouraged. For example, a gradual increase in aerobic PA to 300 min a week of moderate intensity, or $150 \mathrm{~min}$ a week of vigorous intensity aerobic PA, or an equivalent combination thereof, is recommended for additional health benefits.

Specifically for the weight management in an adult overweight or obese population, the included guidelines proposed higher-intensity (duration of at least 6 months) comprehensive lifestyle interventions, including high basic levels (and gradual increase) of PA, diet and behavior change components $[21,26-28,31,35$, 38]. Regular PA with the aim of moderate weight loss is also advised to reduce the risk of Type 2 Diabetes in adults with impaired glucose intolerance and impaired fasting glucose [21, 39, 40]. Five CPGs defined sedentary behavior as an independent CVD risk factor and urged to minimize the amount of time spent being sedentary over extended periods $[18,19,21]$, by advising sedentary people to start PA at low intensity and progress gradually [17], and to reduce screen time and take breaks from prolonged sitting both at home and at work [31].

The included CPGs stated that PA interventions designed in line with these recommendations, will result in a decrease in CVD mortality and morbidity. Moreover, a wide range of indirect health benefits were reported in the guidelines, such as: a decrease of systolic and diastolic blood pressure, body fat, body weight, LDL-C, triglycerides, total cholesterol, HbA1c levels and new onset type 2 diabetes mellitus (T2DM); and an increase of HDL-C and insulin sensitivity.

The recommendations on strategies for delivery and implementation of PA made by the included guidelines, could be structured into eight major categories: Support \& follow up, Behavior change, Provider, Information \& education, Patient-centered care, Self-management, Setting \& referral, and Delivery mode.

Behavior change interventions are recommended to be preceded by raising awareness of the individual CVD risk in relation to lifestyle behavior and an assessment of the 'readiness to change'. It is advised to adapt the timing of such interventions to the stage of motivation, since people are most susceptible for lifestyle change interventions when they are sensitive to change [26]. Guidelines recommended to provide structured counseling targeting lifestyle behaviors $[22,25,28,30]$, incorporating the use of cognitive-behavioral change techniques throughout the multicomponent interventions (e.g. motivational interviewing, shared decision-making, goal-setting, action planning and problem-solving) [17, 19, 24, 28, 35]. Guidelines stated the importance of providing education and communicating clearly with individual patients about all aspects of PA interventions, according to health education principles (e.g. comprehensive amounts of information, reinforced by resources) and using elements of effective communication (e.g. non-judgmental interaction, reflective listening, showing empathy) [31, 32, $35,36]$, hereby creating a shared understanding [21, 28]. Two guidelines also advised to convey tailored messages to local populations using community resources, in order to raise general awareness [17, 40]. Patient-centered care was recommended to entail tailoring interventions to groups and individuals and individualizing care plans throughout the entire follow-up pathway, as interventions are advised to meet individual needs, preferences and circumstances, taking into account social determinants of health [21, 24, 31, 35, 40]. CPGs also proposed to integrate follow-up support and self-management strategies, such as self-monitoring [31], PA tracking [31, 32, 36] and relapse management [26] as part of a multicomponent intervention, in order to ensure that initial behavior change is maintained long-term [19, 24, 28, 36]. The use of mHealth or eHealth applications was proposed to support self-management and follow-up interventions [17, 36].

Team-based multidisciplinary care was advised and guidelines recommended various ways of involving both professional and non-professional care providers $[17,19,21,29,37]$, and linking medical and lay people, peers and family in the planning, design and delivery of interventions [40]. CPGs reported various interprofessional collaboration models with clinicians and non-clinicians, and recommended organizing complementary competencies to be most beneficial for people [17], e.g. by task sharing and shifting in primary health care [36]. We identified several recommendations around community-based support of behavior change interventions through the involvement of community health workers, welfare organizations and social peer support. The included guidelines proposed multifaceted approaches with a clear linkage between primary health care and the community (e.g. by informing people and increase access towards opportunities for increasing PA behavior in the community), in order to increase the effectiveness of interventions [22, 27, 32, 40]. However, they emphasized the importance of embedding lay/peer-led components in a wider team led by health care professionals [40] and underlined the need for appropriate training of both professionals and non-professionals involved in behavior change interventions $[24,36,40]$. CPGs reported various 
advice regarding intensity and frequency of support and follow-up interventions, emphasizing that it is crucial to tailor this to the needs of each individual. They differentiated between very brief, brief or extended brief interventions, and recommended follow-up for at least one year $[15,17,24,36]$. High intensity interventions, with multiple contacts over extended periods, were recommended for active weight management and maintenance in three guidelines [26-28]. The guidelines reported no clear precedence in group versus individual and face to face versus additional remote contacts (e.g. telephone or web-based) [22, 27].

The particular intervention delivery strategies as recommended in the included guidelines, can lead to improvement of the following non-clinical outcomes: Increase of motivation and self-efficacy, better adherence to behavioral elements of the interventions, higher participation and attendance rates in treatment activities, better coping with illness, and higher self-reported health behavior.

\section{Discussion}

The objective of this systematic review of guidelines was to identify recommendations regarding the design and implementation of PA interventions for the primary prevention of CVD on primary health care and community level supporting clinical practice, for the implementation and evaluation in the Horizon 2020 project SPICES sites. Using a systematic and comprehensive approach, we selected 27 high quality CPGs and summarized recommendations on the content of PA advice and provided an overview of recommended strategies for the delivery of PA interventions. The strength of this systematic review and pragmatic summary is that it can guide practitioners in designing and implementing PA interventions, embedded in a broader lifestyle program.

All CPGs alluded to a healthy lifestyle including regular PA as representing a major component of primary CVD prevention and should be recommended to the whole population. These findings are in line with more recent systematic reviews of primary studies, which concluded that given the great health benefits, comprehensively tackling multiple lifestyle risk factors should be the cornerstone for reducing the global disease burden [42, 43]. Overall, the content (frequency, duration, intensity) of the PA message that should be given to the adult population in order to lower their CVD risk, was consistently outlined throughout the included CPGs. In their systematic review, Kraus and colleagues studied the different relationships between PA levels and patient outcomes and found that the associations of PA with beneficial health outcomes begin when adopting even very modest levels; meeting the recommendations reduces mortality and CVD risk to about 75 percent of the maximal benefit obtained by PA alone; and PA levels beyond the guidelines' recommended levels reduce risk even more [44]. Nevertheless, the included CPGs identified an important gap in evidence regarding long-term effectiveness (interventions follow-up beyond 2-3 years), effect on CVD morbidity and mortality and the minimum required PA levels required to gain health benefits. We also found that recommendations remained inconclusive regarding advice on resistance training. Some CPGs suggested that a combination of aerobic PA and resistance training could be effective for people with T2DM, yet limited evidence on effectiveness in CVD protection was reported. Primary studies examining combined resistance and aerobic training reported that taking on both forms of exercise was effective for preventing and managing CVD [45, 46], and it was associated with decreases in body weight, BMI and abdominal subcutaneous fat, and improvements to abdominal fat, visceral fat, cardio-respiratory fitness and HbA1c levels [47]. However, a recent systematic review found insufficient evidence to determine the potential beneficial effect of resistance training on nonfatal events or the effect of substituting aerobic exercise with resistance training [48]. Five of the included CPGs in our review defined sedentary behavior as an independent risk factor for CVD morbidity and mortality. This is in line with a systematic review which concluded that higher levels of total daily sitting time are associated with an increased risk of CVD and diabetes, independent of PA. The authors suggested that reductions in total daily sitting should be recommended in public health guidelines [45]. However, there is insufficient evidence to support the assumption that decreasing sitting time would be easier than effectively promoting PA and evidence remains unclear whether reductions in sedentary time are associated with improvements to the CVD risk [49]. Moreover, given the relative independence of sedentary behavior from PA, it is unsure if existing evidence-based behavioral strategies for increasing PA will also directly decrease sedentary behavior [50].

Various strategies for the delivery of interventions to achieve and sustain behavioral change for healthy lifestyle behaviors such as PA, were recommended by the included guidelines. Most CPGs recommended the use of multicomponent interventions, however, they remained unclear as to which are the most essential components in a package of interventions. Indeed, complex interventions make it difficult to define what exactly are the 'active ingredients' of an intervention and how they relate to each other, due to various interacting components; target behavior(s), groups or organizational levels targeted by the intervention; variability of outcomes; and 
the need for tailoring of the intervention [51]. The use of behavior change techniques was strongly recommended in the included CPGs, although the developers identified an urgent need for future research to examine the most effective approach to deal with multiple behaviors; and the effectiveness of individual techniques on motivation and adherence. Recent studies showed that a combination of education and cognitive-behavioral strategies appears to be more effective than a single intervention [52]. Interventions incorporating cognitive behavioral strategies, including goal-setting, action planning, selfmonitoring, feedback and reinforcement are more likely to induce changes [53], as does increasing self-efficacy and action control skills [54]. In some of the guidelines, technology was recommended as opportunity to improve provider-patient communication, self-monitoring, and patient motivation. Current literature reports a disconnect between behavioral strategies shown to be efficacious in face-to-face studies and the implementation of these strategies in technology-delivered interventions. The most common types of strategies (feedback, self-monitoring, and goal setting) are often integrated in technology interventions, whereas other evidencebased treatment components, e.g. barriers identification, relapse prevention, role modeling, motivational interviewing, are not [50]. Team-based care, involving multidisciplinary professionals, was recommended in the included guidelines. They proposed task shifting and sharing strategies to meet time and resource limitations of primary care staff and in addition, engaging other deliverers in the community. In a systematic review of Fisher et al., peer support was shown to have effects in encouraging and helping to sustain a variety of complex health behaviors in prevention and disease management and in areas such as cardiovascular disease, HIV/AIDS, diabetes and other chronic diseases [55]. Optimizing the engagement of innovative providers requires clear definition of roles and scopes of practice, in-service training and formal supervision, and sensitization of health managers to the importance of counselling [56].

The included CPGs also identified some gaps in research and practice implications. The design and implementation of PA lifestyle interventions do bring resource implications, and guidelines proposed that future research should focus on the most effective and cost-effective ways of developing, implementing and assessing tailored and culturally appropriate interventions on primary care and community level. According to the CPGs, delivery of lifestyle advice requires a rigorous analysis of and tailoring to the context, vulnerable target population and individual. The guidelines reported that there was insufficient evidence available to give specific advice on particular population groups such as ethnic minority groups or different socioeconomic groups; yet they emphasized the importance of identifying and managing the needs of different population groups to address inequalities in health. CPGs could not report consistent information on acceptability and adherence to changes in different population groups, interactions between behaviors and processes for change and (cost-) effectiveness of interventions and strategies for those at higher risk or the entire population. Moreover, the guidelines identified a gap in evidence regarding factors that can influence implementation of the recommendations into practice.

This review has some limitations. All included CPGs in this review were developed in high-income western countries with extensive resources, whereas lowand middle-income countries might require a different approach. Second, our used strategy and instruments did not include an analysis of the CPGs' consistency, meaning that we did not evaluate the underlying strategies of summary and interpretation of the scientific evidence as well as the interpretation and formulation of the recommendations, leading to a possible interpretation bias.

By bringing the advice of current CPGs together in this review, we provided a comprehensive overview of reported evidence-based recommendations for stakeholders that are involved in the design and implementation of PA interventions in primary prevention programs. However, we acknowledge that additional steps are necessary to actually change practice and policy. Implementation studies, such as the SPICES project, can give more insight into contextual barriers and facilitators from the evaluation of implementation outcomes and process, so that closing the chasm between research and practice can be supported.

\section{Conclusions}

Current high-quality CPGs consistently highlight the importance of lifestyle interventions in primary prevention programs for CVD, with PA as one of the major components. PA interventions should be actively integrated in primary health care and community settings. Current clinical practice guidelines recommend similar PA lifestyle advice, and they propose various delivery models to be considered in the design of such interventions. Guidelines identify a gap in evidence on the contextual barriers and facilitators to implementation of these recommendations, urging for future research to focus on closing the gap between research and practice.

\footnotetext{
Abbreviations

CVD: Cardiovascular disease; PA: Physical activity; CPG: Clinical practice guideline; FR: France; ZA: South Africa; UG: Uganda; LSt: Lifestyle behavior guideline; OW: Weight management guideline; LCh: Blood lipids guideline; BP: Blood pressure control guideline; DM: Blood glucose guideline; T2DM:Type 2 diabetes mellitus.
} 


\section{Supplementary Information}

The online version contains supplementary material available at https://doi. org/10.1186/s12875-021-01409-9.

\section{Additional file 1. \\ Additional file 2. \\ Additional file 3. \\ Additional file 4. \\ Additional file 5 .}

\section{Acknowledgements}

Not applicable.

\section{Authors' contributions}

NA, PVR, PVB, GM, LP and HB developed the idea for the systematic review and contributed to the concept and methodology. NA, DLG, MP, JYLR, PVB, PVR and HB performed, collated, and analyzed the search findings. NA drafted the initial manuscript, tables and figures. PVR, GM and HB contributed to the revision of the initial manuscript draft. All authors contributed to the writing of the manuscript and read and approved the final manuscript.

\section{Funding}

This work was funded by the European Commission, as part of a Horizon 2020 project grant for the SPICES project. Project ID: 733356, Funded under: H2020-EU.3.1.6- Health care provision and integrated care. Funding bodies had no role in the design of the study; the collection, analysis and interpretation of the data; nor the decision to approve publication of the final manuscript.

\section{Availability of data and materials}

All data generated or analyzed during this study are included in this published article and its supplementary information files.

\section{Declarations}

\section{Ethics approval and consent to participate}

Not applicable

\section{Consent for publication}

Not applicable.

\section{Competing interests}

Author Paul Van Royen is an Associate Editor of this journal. All other authors declare that they have no competing interests.

\section{Author details}

${ }^{1}$ Department of Primary and Interdisciplinary Care, Faculty of Medicine and Health Sciences, University of Antwerp, Antwerp, Belgium. ${ }^{2}$ Department of General Medicine, SPURBO, Université de Bretagne Occidentale, University of West Brittany, 7479 Brest, EA, France. ${ }^{3}$ Department of Nursing and Midwifery, Faculty of Medicine and Health Sciences, University of Antwerp, Antwerpen, Belgium. ${ }^{4}$ Department of Disease Control and Environmental Health, School of Public Health, College of Health Sciences, Makerere University, Kampala, Uganda.

Received: 23 March 2020 Accepted: 9 March 2021

Published online: 19 May 2021

\section{References}

1. World Health Organization. Facts sheet: Cardiovascular diseases. 2016. [Available from: http://www.who.int/en/news-room/fact-sheets/detail/ cardiovascular-diseases-(cvds).

2. World Health Organization. Cardiovascular diseases: data and statistics. 2016 [Available from: http://www.euro.who.int/en/health-topics/noncommuni cable-diseases/cardiovascular-diseases/data-and-statistics].
3. Yusuf S, Hawken S, Ônpuu S, Dans T, Avezum A, Lanas F, et al. Effect of potentially modifiable risk factors associated with myocardial infarction in 52 countries (the INTERHEART study): case-control study. Lancet. 2004;364(9438):937-52

4. Gaziano TA, Galea G, Reddy KS. Scaling up interventions for chronic disease prevention: the evidence. Lancet. 2007;370(9603):1939-46

5. Stewart J, Manmathan G, Wilkinson P. Primary prevention of cardiovascular disease: a review of contemporary guidance and literature. JRSM Cardiovasc Dis. 2017:6:2048004016687211.

6. Reis RS, Salvo D, Ogilvie D, Lambert EV, Goenka S, Brownson RC. Scaling up physical activity interventions worldwide: stepping up to larger and smarter approaches to get people moving. Lancet (London, England). 2016;388(10051):1337-48.

7. World Health Organization. Global action plan on physical activity 2018-2030: more active people for a healthier world. Geneva: WHO; 2018.

8. Mok A, Khaw KT, Luben R, Wareham N, Brage S. Physical activity trajectories and mortality: population based cohort study. BMJ (Clinical research ed). 2019;365:12323.

9. Fuster V, Kelly BB, Vendanthan R. Global Cardiovascular Health; Urgent Need for an Intersectoral Approach. J Am Coll Cardiol. 2011;58(12):1208-10.

10. Green LW. Closing the chasm between research and practice: evidence of and for change. Health Promot J Austr. 2014;25(1):25-9.

11. Fischer F, Lange K, Klose K, Greiner W, Kraemer A. Barriers and strategies in guideline implementation-a scoping review. Healthcare (Basel, Switzerland). 2016:4(3):36.

12. Higgins JPT, Green S. Cochrane Handbook for Systematic Reviews of Interventions: Wiley; 2011.

13. Moher D, Liberati A, Tetzlaff J, Altman D. Preferred Reporting Items for systematic reviews and meta-Analyses: The PRISMA statement. PLoS Med. 2009;6(7):e1000097.

14. AGREE Next Steps Consortium. The AGREE II Instrument [Electronic Version]. 2009. Available from: http://www.agreetrust.org/.

15. National Vascular Disease Prevention Alliance. Guidelines for the management of absolute CVD risk [Guideline]. 2012 [Available from: https://www.strokefoundation.com.au/ /media/strokewebsite/resou rces/treatment/absolutecvd_gl_webready.ashx?la=en].

16. NICE - National Institute for Health + Care Excellence. Prevention of cardiovascular disease (PH25) [Guideline]. 2010 [updated 31.12.2015. Available from: http://guidance.nice.org.uk/PH25.

17. Piepoli MF, Hoes AW, Agewall S, Albus C, Brotons C, Catapano AL, et al. European guidelines on cardiovascular disease prevention in clinical practice the sixth joint task force of the european society of cardiology and other Societies on cardiovascular disease prevention in clinical Practice (constituted by representatives of 10 societies and by invited experts) developed with the special contribution of the European Association for Cardiovascular Prevention \& Rehabilitation (EACPR). Eur Heart J. 2016;37(29):2315-81.

18. SIGN - Scottish Intercollegiate Guidelines Network. Risk estimation and the prevention of cardiovascular disease (SIGN CPG 149) [Guideline]. 2017 [Available from: http://www.sign.ac.uk/sign-149-risk-estimationand-the-prevention-of-cardiovascular-disease.html].

19. Practitioners N-DCoG. Cardiovascular risk management (M84) Netherlands: NHG; 2019 [updated June 2019. Version 4.0: [Available from: https://richtlijnen.nhg.org/standaarden/cardiovasculair-risicomana gement\#volledige-tekst-literatuur].

20. Atherton JJ, Sindone A, De Pasquale CG, Driscoll A, MacDonald PS, Hopper I. National heart foundation of Australia and cardiac society of Australia and New Zealand: guidelines for the prevention, detection, and management of heart failure in Australia 2018. Heart Lung Circ. 2018;27(10):1123-208.

21. Arnett DK, Blumenthal RS, Albert MA, Buroker AB, Goldberger ZD, Hahn EJ. 2019 ACC/AHA guideline on the primary prevention of cardiovascular disease: a report of the American College of Cardiology/American Heart Association Task Force on Clinical Practice Guidelines. Circulation. 2019;140(11):e596-e646.

22. National Guideline C. Behavioral counseling interventions to promote a healthful diet and physical activity for cardiovascular disease prevention in adults: U.S. Preventive Services Task Force recommendation statement. 2012. 
23. National Guideline C. 2013 AHA/ACC guideline on lifestyle management to reduce cardiovascular risk: a report of the american college of cardiology/american heart association task force on practice guidelines. 2014.

24. NICE - National Institute for Health + Care Excellence. Behaviour change: individual approaches (PH49) [Guideline]. 2014 [Available from: http://guidance.nice.org.uk/PH49].

25. National Guideline C. Screening for and management of obesity in adults: U.S. Preventive Services Task Force recommendation statement. 2012.

26. National Guideline C. Clinical practice guidelines for the management of overweight and obesity in adults, adolescents and children in Australia. 2013.

27. National Guideline C. 2013 AHA/ACC/TOS guideline for the management of overweight and obesity in adults: a report of the American College of Cardiology/American Heart Association Task Force on Practice Guidelines and The Obesity Society. 2014.

28. National Guideline C.VA/DoD clinical practice guideline for screening and management of overweight and obesity. 2014

29. NICE - National Institute for Health + Care Excellence. Obesity (CG43) [Guideline]. 2014 [Available from: http://guidance.nice.org.uk/CG43].

30. National Guideline C. Recommendations for prevention of weight gain and use of behavioural and pharmacological interventions to manage overweight and obesity in adults in primary care. 2015.

31. National Guideline C. Maintaining a healthy weight and preventing excess weight gain among adults and children. 2015.

32. NICE - National Institute for Health + Care Excellence. Cardiovascular disease: risk assessment and reduction, including lipid modifiation (cg181) [Guideline]. 2014 [Available from: http://guidance.nice.org.uk/CG67].

33. National Guideline C. VA/DoD clinical practice guideline for the management of dyslipidemia for cardiovascular risk reduction. 2014.

34. Grundy SM, Stone NJ, Bailey AL, Beam C, Birtcher KK, Blumenthal RS 2018 AHA/ACC/AACVPR/AAPA/ABC/ACPM/ADA/AGS/APhA/ASPC/NLA/ PCNA guideline on the management of blood cholesterol: a report of the American College of Cardiology/American Heart Association Task Force on Clinical Practice Guidelines. Circulation. 2019;139(5):e1082-e1143.

35. Mach F, Baigent C, Catapano AL, Koskinas KC, Casula M, Badimon L. 2019 ESC/EAS Guidelines for the management of dyslipidaemias: lipid modification to reduce cardiovascular risk: the task force for the management of dyslipidaemias of the European Society of Cardiology (ESC) and European Atherosclerosis Society (EAS). Eur Heart J. 2019;41(1):111-88.

36. National Guideline C.VA/DoD clinical practice guideline for the diagnosis and management of hypertension in the primary care setting. 2014.

37. National Guideline C. Team-based care to improve blood pressure control: recommendation of the community preventive services task force. 2014.

38. Rabi DM, McBrien KA, Sapir-Pichhadze R, Nakhla M, Ahmed SB, Dumanski SM. Hypertension Canada's 2020 comprehensive guidelines for the prevention, diagnosis, risk assessment, and treatment of hypertension in adults and children. Can J Cardiol. 2020;36(5):596-624.

39. Cheng AY. Canadian diabetes association 2013 clinical practice guidelines for the prevention and management of diabetes in Canada Introduction. Can J Diabetes. 2013;37(Suppl 1):S1-3.

40. NICE - National Institute for Health + Care Excellence. Preventing type 2 diabetes - population and community interventions (PH35) [Guideline]. 2011 [Available from: http://guidance.nice.org.uk/PH35].

41. Cosentino F, Grant PJ, Aboyans V, Bailey CJ, Ceriello A, Delgado V. 2019 ESC Guidelines on diabetes, pre-diabetes, and cardiovascular diseases developed in collaboration with the EASD: The Task Force for diabetes, pre-diabetes, and cardiovascular diseases of the European Society of Cardiology (ESC) and the European Association for the Study of Diabetes (EASD). Eur Heart J. 2019;1(2):255-323.

42. Zhang YB, Pan XF, Chen J, Cao A, Xia L, Zhang Y, et al. Combined lifestyle factors, all-cause mortality and cardiovascular disease: a systematic review and meta-analysis of prospective cohort studies. J Epidemiol Community Health. 2020.
43. Abbate M, Gallardo-Alfaro L, Bibiloni MDM, Tur JA. Efficacy of dietary intervention or in combination with exercise on primary prevention of cardiovascular disease: a systematic review. Nutr Metab Cardiovasc Dis. 2020;30(7):1080-93.

44. Kraus WE, Powell KE, Haskell WL, Janz KF, Campbell WW, Jakicic JM. Physical Activity, All-Cause and Cardiovascular Mortality, and Cardiovascular Disease. Med Sci Sports Exerc. 2019:51(6):1270-81.

45. Davidson LE, Hudson R, Kilpatrick K, Kuk JL, McMillan K, Janiszewski PM. Effects of exercise modality on insulin resistance and functional limitation in older adults: a randomized controlled trial. Arch Intern Med. 2009:169(2):122-31.

46. Taggart J, Williams A, Dennis S, Newall A, Shortus T, Zwar N. A systematic review of interventions in primary care to improve health literacy for chronic disease behavioral risk factors. BMC Fam Pract. 2012;13:49.

47. Sigal RJ, Kenny GP, Boule NG, Wells GA, Prud'homme D, Fortier M. Effects of aerobic training, resistance training, or both on glycemic control in type 2 diabetes: a randomized trial. Ann Intern Med. 2007;147(6):357-69.

48. Saeidifard F, Medina-Inojosa JR, West CP, Olson TP, Somers VK, Bonikowske AR. The association of resistance training with mortality: A systematic review and meta-analysis. Eur J Prev Cardiol. 2019;26(15):1647-65.

49. de Rezende LF, Rodrigues Lopes M, Rey-Lopez JP, Matsudo VK, Luiz OC. Sedentary behavior and health outcomes: an overview of systematic reviews. PLOS ONE. 2014;9(8):e105620.

50. Lewis BA, Napolitano MA, Buman MP, Williams DM, Nigg CR. Future directions in physical activity intervention research: expanding our focus to sedentary behaviors, technology, and dissemination. J Behav Med. 2017:40(1):112-26.

51. Craig P, Dieppe P, Macintyre S, Michie S, Nazareth I, Petticrew M. Developing and evaluating complex interventions: the new medical research council guidance. BMJ. 2008;337:a1655.

52. Richards EA, Cai Y. Integrative review of nurse-delivered communitybased physical activity promotion applied nursing research. Applied Nursing Res. 2016;31:132-8.

53. Ramoa Castro A, Oliveira NL, ibeiro F, Oliveira J. Impact of educational interventions on primary prevention of cardiovascular disease: A systematic review with a focus on physical activity. Eur J Gen Pract. 2017;23(1):59-68

54. Sniehotta F, Scholz U, Schwarzer R. Bridging the intention-behaviour gap: planning, self-Efficacy, and action control in the adoption and maintenance of physical exercise. 2005. p. 143-60.

55. Fisher EB, Boothroyd RI, Elstad EA, Hays L, Henes A, Maslow GR. Peer support of complex health behaviors in prevention and disease management with special reference to diabetes: systematic reviews. Clin Diabetes Endocrinol. 2017:3:4.

56. Deek H, Hamilton S, Brown N, Inglis SC, Digiacomo M, Newton PJ. Familycentred approaches to healthcare interventions in chronic diseases in adults: a quantitative systematic review. J Adv Nurs. 2016;72(5)968-79.

\section{Publisher's Note}

Springer Nature remains neutral with regard to jurisdictional claims in published maps and institutional affiliations.

Ready to submit your research? Choose BMC and benefit from:

- fast, convenient online submission

- thorough peer review by experienced researchers in your field

- rapid publication on acceptance

- support for research data, including large and complex data types

- gold Open Access which fosters wider collaboration and increased citations

- maximum visibility for your research: over 100M website views per year

At BMC, research is always in progress.

Learn more biomedcentral.com/submissions 